\title{
Numerical Solutions of Stochastic Differential Equations_by using Heun's method
}

\author{
Adel S. Hussain \\ Amedey Institute, Duhok Polytechnic University, Kurdistan Region of Iraq.
}

\begin{abstract}
In this work, we study the numerical method for solving Stochastic differential equations. Because of the difficulty of finding analytical solutions for many of the Stochastic differential equations the Heun's method was used. Numerical simulations for different selected examples are implemented. And the difference between the numerical solution and the exact solution was also found.
\end{abstract}

KEYWORDS : Numerical Solutions, Stochastic Differential Equations Heun's numerical method.

\section{INTRODUCTION}

Early attempts are made in the area of numerical methods for stochastic differential equations using. Heun's method[1,8]. provides an early account for constructing a numerical method for solving stochastic differential equations. This method is known as the Milstein method[1,4,8]. proved an application of the central difference and predictor methods for finding a solution of differential equations with stochastic. Numerical methods for SDE's constructed by translating a deterministic numerical method (like the Heun's method or Runge-Kutta method[6]. and applying it to a stochastic ordinary differential equation. However, merely translating a deterministic numerical method and applying it to an SDE will generally not provide accurate methods [6]. Suitably appropriate numerical methods for SDE's should take into account a detailed analysis of the order of convergence as well as stability of the numerical scheme and the behavior of the errors. The Heun's method for SDE's is the simplest method which is a direct translation of the deterministic Heun's method, but according to $[4,9]$ this method is not very accurate. However, this method is useful in that it provides a starting point for more advanced numerical methods for SDE's. Our work is solving stochastic differential

Academic Journal of Nawroz University

(AJNU) Volume 7, No 3 (2018).

Received 10 April 2018;

Regular research paper : Published 20 July 2018

Corresponding author's e-mail : adel.sufian@gmail.com

Copyright (C2018 Adel S. Hussain.

This is an open access article distributed under the

Creative Commons Attribution License. equation, by using Heun's (modified Euler's method).Moreover we use some examples to show that the numerical solutions of different examples are implemented properly.

Definition 1.1.[6].

Let $\mathrm{x}(\mathrm{t}) \in(0 \leq \mathrm{t} \leq \mathrm{T})$ be a stochastic process such that for any $0 \leq t_{1}<t_{2} \leq T$

$x\left(t_{2}\right)-x\left(t_{1}\right)=\int_{t_{1}}^{t_{2}} a(t) d t+\int_{t_{1}}^{t_{2}} b(t) d w(t)$

where $a \in \mathrm{L}_{\omega}^{1}[0, T], b \in \mathrm{L}_{\omega}^{2}[0, T]$. Then we say that $x(t)$ has stochastic differential $\mathrm{dx}$, on $[0, \mathrm{~T}]$, given by :

$d x(t)=a(t) d t+b(t) d w(t)$

Observe that $x(t)$ is a no anticipative function. It is also a continuous process. Hence, in particular, it belongs to

$\mathrm{L}_{\omega}^{\infty}[0, \mathrm{~T}]$.

Definition 1.2.[7].

Let $x(t)$ be as in definition (1) and let $f(t)$ be a function in $\mathrm{L}_{\omega}^{\infty}[0, \mathrm{~T}]$. We define :

$f(t) d x(t)=f(t) a(t) d t+f(t) b(t) d w(t)$.

Theorem 1.1.[7].

Let $d \xi(t)=a d t+b d w(t)$, and let $f(x, t)$ be a continuous function in $(\mathrm{x}, \mathrm{t}) \quad \mathrm{R}^{1} \times[0, \infty) \quad$ with partial derivatives $f_{x}, f_{x x}, f_{t}$. Then the process $f(\xi(t), t)$ has a stochastic differential, given by :

$d f(\xi(t), t)=\left[f_{t}(\xi(t), t)+f_{x}(\xi(t), t) a(t)+\frac{1}{2} f_{x x}(\xi(t), t) b^{2}(t)\right] d t+$ $f_{x}(\xi(t), t) b(t) d w(t)$

This is called the Itô formula. Notice that if $w(t)$ were continuously differentiable in $t$, then (by the standard calculus formula for total derivatives) the term $\frac{1}{2} f_{x x} b^{2} d t$ will not appear. 


\section{Vector SDE's [6].}

We shall interpret a vector as a column vector and its transpose as a row vector and consider an mdimensional

Wiener process $\mathrm{w}=\left\{\mathrm{w}_{\mathrm{t}}, \mathrm{t} \geq 0\right\}$, with components $\mathrm{w}_{\mathrm{t}}{ }^{1}, \mathrm{w}_{\mathrm{t}}{ }^{2}$, $\ldots, \mathrm{w}_{\mathrm{t}}{ }^{\mathrm{m}}$ which are independent scalar Wiener process.

Then, we take a k-dimensional vector values function a : $\left[\mathrm{t}_{0}, \mathrm{~T}\right] \times \mathrm{R}^{\mathrm{k}} \longrightarrow \mathrm{R}^{\mathrm{k}}$, the drift coefficients, and a k $\times$ m-matrix valued function $b:\left[\mathrm{t}_{0}, \mathrm{~T}\right] \times \mathrm{R}^{\mathrm{k}} \longrightarrow \mathrm{R}^{\mathrm{k} \times \mathrm{m}}$, the diffusion coefficient, $\mathrm{t}_{0} \in[0, \mathrm{~T}]$, to form a $\mathrm{k}$-dimensional vector stochastic differential equation :

$d x_{t}=a\left(t, x_{t}\right) d t+b\left(t, x_{t}\right) d w_{t}$

we interpret this as a stochastic integral equation :

$\mathrm{x}_{\mathrm{t}}=\mathrm{x}_{0}+\int_{\mathrm{t}_{0}}^{\mathrm{t}} \mathrm{a}\left(\mathrm{s}, \mathrm{x}_{\mathrm{s}}\right) \mathrm{ds}+\int_{\mathrm{t}_{0}}^{\mathrm{t}} \mathrm{b}\left(\mathrm{s}, \mathrm{x}_{\mathrm{s}}\right) d w \mathrm{~s}$

with initial value $x_{t_{0}} \in R^{k}$, where the Lebsegue and Itô integrals determined component by component, with the component of (3) being :

$\mathrm{x}^{\mathrm{i}}{ }_{\mathrm{t}}=\mathrm{x}_{\mathrm{t}_{0}}^{\mathrm{i}}+\int_{\mathrm{t}_{0}}^{\mathrm{t}} \mathrm{a}^{\mathrm{i}}\left(\mathrm{s}, \mathrm{x}_{\mathrm{s}}\right) \mathrm{ds}+\sum_{\mathrm{j}=1}^{\mathrm{m}} \int_{\mathrm{t}_{0}}^{\mathrm{t}} \mathrm{b}^{\mathrm{i}, \mathrm{j}}\left(\mathrm{s}, \mathrm{x}_{\mathrm{s}}\right) \mathrm{d} \mathrm{w}_{\mathrm{s}}^{\mathrm{j}}{ }_{\mathrm{s}}$

$\mathrm{i}=1,2, \ldots, \mathrm{n}$

If the drift and diffusion coefficients do not depend on the time variable, that is if $a(t, x) \equiv b(x)$, then we say that the stochastic equation is autonomous. We can always write a no autonomous equation as a vector autonomous equation of one dimension more by setting in the drift component the component of $x_{t}$ the time variable $\mathrm{w}_{\mathrm{t}}{ }^{1}=\mathrm{t}$. There is a vector version of the Itô formula. For a sufficiently smooth transformation $f=$ $\left[\mathrm{t}_{0}, \mathrm{~T}\right] \times \mathrm{R}^{\mathrm{d}} \longrightarrow \mathrm{R}^{\mathrm{k}}$

of the solution $x=\left\{x_{t}, t_{0} \leq t \leq T\right\}$ of (2), we obtain a kdimensional process and $\mathrm{y}=\left\{\mathrm{y}_{\mathrm{t}}=\mathrm{f}\left(\mathrm{t}, \mathrm{x}_{\mathrm{t}}\right), \mathrm{t}_{0} \leq \mathrm{t} \leq \mathrm{T}\right\}$ with the vector stochastic differential in component form $\mathrm{d} y^{t}{ }_{p}=$

$\left(\frac{\partial \mathbf{f}^{\mathrm{p}}}{\partial \mathrm{t}}+\sum_{\mathrm{i}=1}^{\mathrm{d}} \mathrm{a}^{\mathrm{i}} \frac{\partial \mathrm{f}^{\mathrm{p}}}{\partial \mathrm{x}_{\mathrm{i}}}+\frac{1}{2} \sum_{\mathrm{i}, \mathrm{j}=1}^{\mathrm{d}} \sum_{\ell=1}^{\mathrm{m}} \mathbf{b}^{\mathrm{i}, \ell} \mathbf{b}^{\mathrm{j}, \ell} \frac{\partial^{2} \mathrm{f}^{\mathrm{p}}}{\partial \mathrm{x}_{\mathrm{i}} \partial \mathrm{x}_{\mathrm{j}}}\right) \mathrm{dt}{ }^{+}$ $\sum_{\ell=1}^{\mathbf{m}} \sum_{\mathbf{i}=1}^{\mathbf{d}} \mathbf{b}^{\mathbf{i}, \ell} \frac{\partial \mathbf{f}^{\mathbf{p}}}{\partial \mathbf{x}_{\mathbf{i}}} \mathbf{d} \mathbf{W}_{\mathbf{t}}^{\ell}$

for $\mathrm{p}=1,2, \ldots, \mathrm{k}$; where the terms are all evaluated at $(\mathrm{t}$, $\left.X_{t}\right)$.

3. Generating Brownian Motion in Matlab[7].

The underlying difference between deterministic and probabilistic differential equations is to need generate the following random increments of the Brownian motion for the SDE

$\Delta \mathrm{w}_{\mathrm{n}}=w_{t_{n}}-w_{t_{n-1}}$

For computational purpose, it is necessary to describe the Brownian motion, where $\mathrm{w}_{\mathrm{t}}$ is specified at discrete $\mathrm{t}$ values. Therefore, let $\Delta t=T / N$, for some positive integer $\mathrm{N}$ and for $\mathrm{T}$ on the interval $[0, \mathrm{~T}]$. From the definition of Brownian motion :

$\Delta \mathrm{w}_{\mathrm{n}}=w_{t_{n}}-w_{t_{n-1}} \sim \mathrm{N}\left(0, \mathrm{t}_{\mathrm{n}}-\mathrm{t}_{\mathrm{n}-1}\right)$ or equivalently :

$\Delta \mathrm{w}_{\mathrm{n}}=w_{t n}-w_{t n-1} \sim \sqrt{\mathrm{t}_{\mathrm{n}}-\mathrm{t}_{\mathrm{n}-1}} \mathrm{~N}(0,1)$

where $\mathrm{N}(0,1)$ denotes a standard normally distributed random variable with zero mean and variance equal to one. Here $t_{n}-t_{n-1}=\Delta t$ is the variance of the Brownian motion random variable. In Mat lab, the function randn $(\mathbf{1}, \mathbf{N})$ will generate $\mathrm{N}$ random variables from the standard normal distribution. In order to generate a random variable with variance equal to $\Delta \mathrm{t}$, random variables from the standard normal distribution are generated using the Mat lab

function randn $(\mathbf{1}, \mathbf{N})$ and each of $(2$ these variables are then multiplied by $\sqrt{\Delta t}$, resulting in the random increments

in equation (4). From equation (4) :

Implying that

$$
\begin{aligned}
& \Delta \mathrm{w}_{1}=w_{t_{1}}-w_{t_{0}} \\
& \Delta \mathrm{w}_{2}=w_{t_{2}}-w_{t_{1}}
\end{aligned}
$$

$\Delta \mathrm{w}_{1}+\Delta \mathrm{w}_{2}=\mathrm{w}_{\mathrm{t}_{2}}-\mathrm{w}_{\mathrm{t}_{1}}+\mathrm{w}_{\mathrm{t}_{1}}-\mathrm{w}_{\mathrm{t}_{0}}=\mathrm{w}_{\mathrm{t}_{2}}$

and since $t_{0}=0$ when $\mathrm{W}_{0}=0$, when therefore

$\mathrm{w}_{\mathrm{t}_{\mathrm{n}}}=\sum_{\mathrm{j}=1}^{\mathrm{n}} \Delta \mathrm{w}_{\mathrm{j}}$

For more details, see the computational algorithm for generating Brownian motion supported by Mat lab

\section{Stochastic Taylor Expansion [9].}

We consider the equation $\mathrm{x}=\left\{\mathrm{x}_{\mathrm{t}}, \mathrm{t} \in\left[\mathrm{t}_{0}, \mathrm{~T}\right]\right\}$ of onedimensional stochastic ordinary differential equation :

$\frac{d}{d t} x_{t}=\mathrm{a}\left(x_{t}\right)$

with initial value $x_{t 0}$, for $\mathrm{t} \in\left[\mathrm{t}_{0}, \mathrm{~T}\right]$, where $0 \leq \mathrm{t}_{0} \leq t \leq \mathrm{T}$, which we can write in the equivalent integral equation

form as :

$x_{t}=x_{t_{0}}+\int_{t_{0}}^{t} a\left(x_{s}\right) d s$

To justify the following constructions we require that the function a satisfies appropriate properties, for instance to be sufficiently smooth with a linear growth bound. Let $\mathrm{f}: R \longrightarrow R$ be continuously differentiable function.

Then by the chain rule, we have :

$\frac{d}{d t} \mathrm{f}\left(x_{t}\right)=\mathrm{a}\left(x_{t}\right) \mathrm{f}\left(x_{t}\right)$

Which using the operator $\mathrm{Lf}=\mathrm{af}$

we can express (6) as the integral relation

$\mathrm{f}\left(x_{t}\right)=\mathrm{f}\left(x_{t_{0}}\right)+\int_{t_{0}}^{t} L f\left(x_{s}\right) d s$

for all $\mathrm{t} \in\left[\mathrm{t}_{0}, \mathrm{~T}\right]$. When $\mathrm{f}(\mathrm{x})=\mathrm{x}$, we have $\mathrm{Lf}=\mathrm{a}, \mathrm{L}^{2} \mathrm{f}=\mathrm{La}$, $\ldots$ and (7) reduces to :

$x_{t}=x_{t_{0}}+\int_{t_{0}}^{t} a\left(x_{s}\right) d s$

That is equation (5). If we apply the equation (7) to the function $\mathrm{f}=\mathrm{a}$ in the inte gral in (8), we obtain that

$$
\begin{gathered}
x_{t}=x_{t_{0}}+\int_{t_{0}}^{t}\left[a\left(x_{t_{0}}\right)+\int_{t_{0}}^{s} L a\left(x_{z}\right) d z\right] d s \\
=x_{t_{0}}+\mathrm{a}\left(x_{t_{0}}\right) \int_{t_{0}}^{t} d s+\int_{t 0}^{t} \int_{t 0}^{s} L a\left(x_{z}\right) d z d s
\end{gathered}
$$


which is the simplest nontrivial Taylor expansion for $\mathrm{X}_{\mathrm{t}}$. Also can apply (7) again to the function $\mathrm{f}=\mathrm{La}$ in the double integral of (9) we have

$x_{t}=x_{t_{0}}+\mathrm{a}\left(x_{t_{0}}\right) \int_{t_{0}}^{t} d s+\mathrm{La}\left(x_{t_{0}}\right) \int_{t_{0}}^{t} \int_{t_{0}}^{s} d z d s+\mathrm{R}_{3}$

where

$\mathrm{R}_{3}=\int_{\mathrm{t} 0}^{\mathrm{t}} \int_{\mathrm{t} 0}^{\mathrm{s}} \int_{\mathrm{t} 0}^{\mathrm{z}} \mathrm{L}^{2} \mathrm{a}\left(\mathrm{x}_{\mathrm{u}}\right)$ dudzds.

for $\mathrm{t} \in\left[\mathrm{t}_{0}, \mathrm{~T}\right]$. For a general $\mathrm{r}+1$ times continuously differentiable function $\mathrm{f}: R \longrightarrow R$, this method gives the classical Taylor formula in integral form

$\mathrm{f}\left(x_{t}\right)=\mathrm{f}\left(x_{0}\right)+\sum_{l=1}^{r} \frac{\left(t-t_{0}\right)^{l}}{l !} L^{l} f\left(x_{t}\right)+\int_{t 0}^{t} \ldots \int_{t 0}^{s_{2}} L^{r+1} f\left(x_{s_{1}}\right) d s_{1}$ for $\mathrm{t} \in\left[\mathrm{t}_{0}, \mathrm{~T}\right]$ and $\mathrm{r}=1,2, .$. ; since

$\int_{\mathrm{t}_{0}}^{\mathrm{t}} \int_{\mathrm{t}_{\mathrm{O}}}^{\mathrm{s}_{1}} \ldots \int_{\mathrm{t}_{\mathrm{O}}}^{\mathrm{s}_{\ell-1}} \mathrm{ds}_{1} \ldots \mathrm{ds} \mathrm{s}_{\ell}=\frac{1}{\ell !}\left(\mathrm{t}-\mathrm{t}_{0}\right)^{\ell}$ For $l=1,2, \ldots$

By repeatedly applying the Itô formula (3). For any twice continuously differentiable function $\mathrm{f}: R \longrightarrow R$ and apply the

ItÔ formula to obtain

$\mathrm{f}\left(x_{t}\right)=\mathrm{f}\left(x_{t_{0}}\right)+\int_{t_{0}}^{t}\left[a\left(x_{1}\right) f^{\prime}\left(x_{1}\right)+\right.$ $\left.\frac{1}{2} b^{2}\left(x_{1}\right) f^{\prime \prime}\left(x_{1}\right)\right] d s+\int_{t_{0}}^{t} b\left(x_{1}\right) f^{\prime}\left(x_{1}\right) d x_{1}$

Introduce the following operators :

$\mathrm{L}^{0} \mathrm{f}=\mathrm{af}^{\prime}+\frac{1}{2} \mathrm{~b}^{2} \mathrm{f}^{\prime \prime}, \quad \mathrm{L}^{1} \mathrm{f}=\mathrm{bf}^{\prime} \ldots(11)$

So that

$\mathrm{f}\left(x_{t}\right)=\mathrm{f}\left(x_{t_{0}}\right)+\int_{t_{0}}^{t} L^{0} f\left(x_{1}\right) d s+\int_{t_{0}}^{t} L^{1} f\left(x_{1}\right) d w 1 \ldots(12)$

for any $\mathrm{t} \in\left[\mathrm{t}_{0}, T\right]$. If $\mathrm{f}(\mathrm{x})=\mathrm{x}$, then $\mathrm{L}^{0} \mathrm{f}=\mathrm{a}$ and $\mathrm{L}^{1} \mathrm{f}=\mathrm{b}$.

Thus, the above is just the original It $\hat{O}$ equation for $X_{1}$ $x_{t}=x_{t_{0}}+\int_{t_{0}}^{t} a\left(x_{s}\right) d s+\int_{t_{0}}^{t} b(x s) d w s$

Apply (11) the functions $\mathrm{f}=\mathrm{a}$ and $\mathrm{b}$ in equation (13), the following is obtained :

$$
\begin{aligned}
& x_{\mathrm{t}}=\quad x_{t_{0}}+\quad \int_{t_{0}}^{t}\left(a\left(x_{t_{0}}\right)+\int_{t_{0}}^{s} L^{0} a\left(x_{z}\right) d z+\right. \\
& \left.\int_{t_{0}}^{s} L^{0} a\left(x_{z}\right) d w_{z}\right) d s+\int_{t_{0}}^{t}\left(b\left(x_{t_{0}}\right)+\int_{t_{0}}^{s} L^{0} b\left(x_{z}\right) d z+\right. \\
& \left.\int_{t_{0}}^{s} L^{0} b\left(x_{z}\right) d w_{z}\right) d w_{z} \\
& \quad=x_{t_{0}}+a\left(x_{t_{0}}\right) \int_{t_{0}}^{t} d s+b\left(x_{t_{0}}\right) \int_{t_{0}}^{t} d w_{z}+\text { R...(14) }
\end{aligned}
$$

Where

$$
\begin{aligned}
& \mathrm{R}=\int_{\mathrm{t}_{\mathbf{O}}}^{\mathrm{t}} \int_{\mathrm{t}_{\mathbf{O}}}^{\mathrm{z}} \mathrm{L}^{0} \mathrm{a}\left(\mathrm{X}_{\mathrm{z}}\right) \mathrm{dzds}+\int_{\mathrm{t}_{\mathbf{O}}}^{\mathrm{t}} \int_{\mathrm{t}_{\mathbf{O}}}^{\mathrm{z}} \mathrm{L}^{1} \mathrm{a}\left(\mathrm{X}_{\mathrm{z}}\right) \mathrm{dw} \mathrm{w}_{\mathrm{z}} \mathrm{ds}+ \\
& \int_{t_{0}}^{t} \int_{t_{0}}^{z} L^{0} b\left(X_{z}\right) d z d w_{s}+\int_{t_{0}}^{t} \int_{t_{0}}^{z} L^{0} b\left(X_{z}\right) d w_{z} d w_{s}
\end{aligned}
$$

Repeat this procedure by applying the formula (12) to $\mathrm{f}$ $=\mathrm{L}^{1} \mathrm{f}$ in equation (14) to obtain :

$$
\begin{aligned}
& x_{t} \quad=x_{t_{0}}+a\left(x_{t_{0}}\right) \int_{t_{0}}^{t} d s+b\left(x_{t_{0}}\right) \int_{t_{0}}^{t} d w_{z}+ \\
& \mathrm{L}^{1} \mathrm{~b}\left(x_{t_{0}}\right) \int_{t_{0}}^{t} \int_{t_{0}}^{z} d w_{z} d w_{s}+\overline{\mathrm{R}} \ldots .(15) \\
& \text { Where }
\end{aligned}
$$

$\overline{\mathrm{R}}=\int_{\mathrm{t}_{0}}^{\mathrm{t}} \int_{\mathrm{t}_{0}}^{\mathrm{s}} \mathrm{L}^{0} \mathrm{a}\left(\mathrm{x}_{\mathrm{z}}\right) \mathrm{dzds}+\int_{\mathrm{t}_{0}}^{\mathrm{t}} \int_{\mathrm{t}_{0}}^{\mathrm{s}} \mathrm{L}^{1} \mathrm{a}\left(\mathrm{x}_{\mathrm{z}}\right) \mathrm{dw} \mathrm{w}_{\mathrm{z}} \mathrm{ds}+$

$\int_{\mathbf{t}_{0}}^{\mathrm{t}} \int_{\mathrm{t}_{0}}^{\mathrm{s}} \mathrm{L}^{0} \mathrm{~b}\left(\mathrm{x}_{\mathrm{z}}\right) \mathrm{dzdw_{ \textrm {s } }}+\int_{\mathrm{t}_{0}}^{\mathrm{t}} \int_{\mathrm{t}_{0}}^{\mathrm{s}} \int_{\mathrm{t}_{0}}^{\mathrm{z}} \mathrm{L}^{0} \mathrm{~L}^{1} \mathrm{~b}(\mathrm{u}) d u d w_{z} d w_{\mathrm{s}}+$

$\int_{0}^{t} \int_{0}^{s} \int_{0}^{z} L^{1} L^{1} b\left(X_{u}\right) d w_{u} d w_{z} d w_{s}$

$\int_{\mathbf{t}_{\mathrm{O}}} \int_{\mathbf{t}_{\mathrm{O}}} \int_{\mathbf{t}_{\mathrm{O}}}$

The ItÔ -Taylor expansion can thus be considered as a generalization of both the It $\hat{O}^{(10}$ formula and the deterministic Taylor formula.

5.Main Results :

In this section The Heun's method applying to SDE is by of the Heun's(modified Euler's method)

Consider the following SDE : -

$$
d y_{t}=a\left(t, x_{t}\right) d t+b\left(t, x_{t}\right) d \ldots(16)
$$

Where $a\left(t, x_{t}\right), b\left(t, x_{t}\right)$ are continuous functions which are defined on interval $\left[t_{0}, T\right]$.

Now, if we integrate the SDE the equation (16), we get

$$
y\left(x_{1}\right)=y\left(x_{0}\right)+\int_{x_{0}}^{x_{1}} a\left(s, x_{s}\right) d s+\int_{t_{0}}^{t} b\left(s, x_{s}\right) d w_{s} \ldots(17)
$$

Also let $\quad I_{1}=\int_{t_{0}=x_{0}}^{t=x_{1}} a\left(s, x_{s}\right) d s=\int_{t_{0}=x_{0}}^{t=x_{1}} f(x) d x$

where trapezoidal rule $x_{0}=t_{0}, x_{1}=t, \mathrm{~h}=x_{0}-x_{1}=$ $t_{0}-t$.

And $f(x)=P_{n}(x)+\frac{f^{n+1}(\delta)}{(n+1) !} \prod_{i=0}^{n}\left(x-x_{i}\right) \ldots(18)$

Provided that $P_{n}(x)=\sum_{\substack{i=0 \\ i \neq k}}^{n} f\left(x_{i}\right) * L_{i}(x)$, where $L_{i}(x)$ $=\sum_{\substack{i=0 \\ i \neq k}}^{n} \frac{X-X_{i}}{X_{k}-X_{i}}$

And,also $\quad \mathrm{n}=1 \rightarrow P_{1}(x)=\sum_{\substack{i=0 \\ i \neq k}}^{1} f\left(x_{i}\right) * \frac{X-X_{i}}{X_{k}-X_{i}}=\frac{X-X_{1}}{X_{0}-X_{1}} *$ $f\left(x_{0}\right)+\frac{X-x_{0}}{X_{1}-X_{0}} * f\left(x_{1}\right)$

Hence

$$
\begin{aligned}
& f(x)=\frac{x-X_{1}}{X_{0}-X_{1}} * f\left(x_{0}\right)+\frac{x-X_{0}}{X_{1}-X_{0}} * f\left(x_{1}\right)+ \\
& \frac{f^{(n+1)}(\varepsilon)}{(n+1) !} \prod_{i=0}^{n}\left(x-x_{i}\right)
\end{aligned}
$$

Also if $I_{1}=\int_{t_{0}=x_{0}}^{t=x_{1}} f(x) d x=\int_{t_{0}=x_{0}}^{t=x_{1}}\left(\frac{x-x_{1}}{x_{0}-x_{1}} * f\left(x_{0}\right)+\right.$ $\left.\frac{X-X_{0}}{X_{1}-X_{0}} * f\left(x_{1}\right)\right) d x+\int_{t_{0}=x_{0}}^{t=x_{1}} \frac{f^{(n+1)}(\varepsilon)}{(n+1) !} \prod_{i=0}^{n}\left(x-x_{i}\right) d x$.

Where

Then

$$
\int_{t_{0}=x_{0}}^{t=x_{1}} \frac{f^{(n+1)}(\varepsilon)}{(n+1) !} \prod_{i=0}^{n}\left(x-x_{i}\right) d x \text { is called error }
$$

$$
\begin{aligned}
& \quad I_{1}=\int_{t_{0}=x_{0}}^{t=x_{1}} f(x) d x=\int_{t_{0}=x_{0}}^{t=x_{1}}\left\{\frac{\left(x-x_{1}\right)^{2}}{2\left(x_{0}-x_{1}\right)} * f\left(x_{0}\right)+\right. \\
& \left.\frac{\left(x-x_{0}\right)^{2}}{2\left(x_{1}-x_{0}\right)} * f\left(x_{1}\right)\right\} d x=\frac{x_{1}-x_{0}}{2}\left[f\left(x_{0}\right)+f\left(x_{1}\right)\right]= \\
& \frac{h}{2}\left[f\left(x_{0}\right)+f\left(x_{1}\right)\right] \ldots(19) \\
& \text { And } \quad I_{2}=\int_{t_{0}}^{t} b\left(x_{s}\right) d w_{s}=\int_{t_{0}=x_{0}}^{t=x_{1}} b\left(s, x_{s}\right) d w_{s}= \\
& \int_{t_{0}=x_{0}}^{t=x_{1}} b(x) d w=\frac{X_{1}-x_{0}}{2}\left[b\left(x_{0}\right)+b\left(x_{1}\right)\right] \ldots(20) \\
& \text { Since Euler Scheme method which is } x_{t}=x_{t_{0}}+a \Delta n+
\end{aligned}
$$
$b \Delta w_{n}$ 
Or $\quad y_{n+1}=y_{n}+a \Delta n+b \Delta w_{n} ; n=0,1,2, \ldots, N-1$

...(21)

Then Substitute. Equation (21) in equations (19), (20), we get

$I_{1}=\frac{h}{2}\left[f\left(y_{n}\right)+f\left(y_{n}+a \Delta n+b \Delta w_{n}\right)\right], \quad$ and $\quad I_{2}=$

$\frac{h}{2}\left[b\left(y_{n}\right)+b\left(y_{n}+a \Delta n+b \Delta w_{n}\right)\right] \ldots .(22)$

where $\mathrm{x}=\left\{\mathrm{x}_{\mathrm{t}}: \mathrm{t}_{0} \leq \mathrm{t} \leq \mathrm{T}\right\}$ is an Itô process with initial value $x_{t_{0}}=x_{0}$. Subdivide the interval $\left[\mathrm{t}_{0}, \mathrm{~T}\right]$ into $\mathrm{N}$ subintervals according to the following discretization : $\mathrm{t}_{0}=\tau_{0}<\tau_{1}<\ldots<\tau_{\mathrm{n}}<\ldots<\tau_{\mathrm{N}}=\mathrm{T}$.

The heun's approx. is defined as cont.time stochastics pr $\left\{y(T) ; t_{0} \leq t<T\right\}$ satisfying the iterative scheme :

$y_{n+1}=y_{n}+\frac{h}{2}\left[f\left(y_{n}\right)+f\left(p_{i+1}\right)\right] \Delta n+\frac{h}{2}\left[b\left(y_{n}\right)+\right.$ $b\left(p_{i+1}\right) \mid \Delta w_{n} \ldots(23)$

for $\mathrm{n}=0,1, \ldots, \mathrm{N}-1$; with initial value $\mathrm{y}_{0}=\mathrm{x}_{0}$.

Remark1.

Equation (23) is the It $\hat{O}$-Taylor expansion of $x_{t}(\omega)$ in equation (17). The Itô-Taylor expansion is useful in approximating a sufficiently smooth function in a neighborhood of a given point to a desired order of accuracy. Thus, considering the first three terms of equation (23) provides the Heun's scheme in (23) where each term in the right hand side of equation (23) approximates the corresponding term on the right hand side of equation (17). For brevity, equation (23) is written as :

$\mathrm{Y}_{\mathrm{n}+1}=\mathrm{Y}_{\mathrm{n}}+\mathrm{a} \Delta \mathrm{n}+\mathrm{b} \Delta \mathrm{W}_{\mathrm{n}}$

where

$$
\begin{gathered}
p_{i+1}=y_{n}+a \Delta n+b \Delta w_{n} \\
\text { And } \Delta n=t-t_{0}=\int_{t_{0}}^{t} d s, \quad \Delta w_{n}=x_{t_{n+1}}-x_{t_{n}}= \\
\int_{t_{0}}^{t} d w_{s}, \mathrm{a}=\mathrm{a}\left(\tau_{\mathrm{n}}, \mathrm{y}\left(\tau_{\mathrm{n}}\right)\right), \mathrm{b}=\mathrm{b}\left(\tau_{\mathrm{n}}, \mathrm{y}\left(\tau_{\mathrm{n}}\right)\right) \text {, and } \mathrm{y}_{\mathrm{n}}=\mathrm{y}\left(\tau_{\mathrm{n}}\right)
\end{gathered}
$$

Remark2.

The Heun's scheme for a deterministic ordinary differential equations is obtained if $b=0$ in equation (23). Thus, the main difference between the Heun's scheme for deterministic ordinary differential equations and the Heun's scheme for SDE's is the following random increments need to be generated for the SDE :

$\Delta \mathrm{w}_{\mathrm{n}}=\mathrm{x}_{\mathrm{t}_{\mathrm{n}+1}}-\mathrm{x}_{\mathrm{t}_{\mathrm{n}}}$

for $\mathrm{n}=0,1, \ldots, \mathrm{N}-1$; of the Wiener process $\mathrm{w}=\left\{\mathrm{w}_{\mathrm{t}}, \mathrm{t} \geq\right.$ $0\}$, (see defined(1.1) in [6]).

Remark 3.

The Heun's scheme determines values of the approximating process at the discretization times only. The values at the intermediate instances can be calculated by using either the piecewise constant interpolation method or the linear interpolation method. An overview method is provided in [8].The
Heun's scheme is an example of a time discrete approximation (or difference method) in which the continuous time differential equation is replaced by a discrete time difference equation generating values $Y_{1}$, $\mathrm{Y}_{2, . .,} \mathrm{Y}_{\mathrm{n}}$ to approximate $x_{t_{1}}, x_{t_{2}}, \ldots, x_{t_{n}}$ at given discretization times $t_{0}<t_{1}<\ldots<t_{n}$. The Heun's scheme is the simplest strong Taylor approximation and attains an order of convergence when $\gamma=0.5$.

\subsection{Algorithm and Illustration :}

Algorithm (Euler-Maruyama Method) :

Input : The dynamic stochastic differential equation in dresblem formulation :

$$
\left.\begin{array}{c}
d x(t)=f\left(x_{t}, t\right) d t+g\left(x_{t}, t\right) d w(t) \\
x(0)=x_{0}
\end{array}\right\}
$$

Output : Numerical (sample path) solution of stochastic process.

Step 1 : Consider problem formulation (24).

Step 2 : Generating a Brownian motion.

Step 2.1 : Generate a random number.

Step 2.2: Consider $\mathrm{T}=\mathrm{t}_{0} ; \mathrm{N}=\mathrm{n}_{0} ; \mathrm{dt}=\mathrm{T} / \mathrm{N}$.

Step 2.3: $\mathrm{W}(\mathrm{t}) \sim \mathrm{N}(0,1)$.

Step 2.4: $W_{0}=0$ with probability 1 .

Step 2.5: $W_{j}=W_{j-1}+d W_{j}, j=1,2, \ldots, N$.

Step 2.6: $\mathrm{dW}_{\mathrm{j}} \sim \sqrt{\delta_{\mathrm{t}}} \mathrm{N}(0,1)$.

Step $3:$ Set $\mathrm{j}=1 \longrightarrow \mathrm{L}$

$\mathrm{W}\left(\mathrm{T}_{\mathrm{j}}\right)-\mathrm{W}\left(\mathrm{T}_{\mathrm{j}-1}\right)=\mathrm{W}\left(\mathrm{j} R \delta_{\mathrm{t}}\right)-\mathrm{W}\left((\mathrm{j}-1) \mathrm{R} \delta_{\mathrm{t}}\right)=$

$\sum_{k=j R-R+1}^{j R} d W_{k}$

$X_{j}=X_{j-1}+\frac{h}{2} f\left(X_{j-1}\right) \Delta t+\frac{h}{2} g\left(X_{j-1}\right)\left(W\left(T_{j}\right)-W\left(T_{j-1}\right)\right)$,

If $\mathrm{j} \geq \mathrm{L}$ stop.

Step 4 : Computation of error, depending on the type of error for example, the following is absolute error

Step $4.1:$ If $\Delta t=\delta_{t}$

Set $\mathrm{i}=1 \longrightarrow \mathrm{L}$

error $=\operatorname{abs}\left(X_{n}(i)-X_{T}(i)\right)$

Step 4.2: If $\Delta t \neq \delta_{t} \quad ; \quad$ error $=\operatorname{abs}\left(X_{n}(\right.$ final $)-X_{T}($ final $\left.)\right)$. I.Illustration. (With Absolute Error Test) :

Consider the SDE is :

$d X=f d t+g d W$

$X(0)=1$

Where $\mathrm{f}(\mathrm{t}) \quad=\int_{0}^{\mathrm{t}} \cos \left(\int_{0}^{\mathrm{s}} \sin \mathrm{s} \mathrm{ds}\right) \mathrm{dx} ; \mathrm{g}(\mathrm{t})=$ $\int_{0}^{\mathrm{t}} \sin \left(\int_{0}^{\mathrm{s}} \operatorname{tans} \mathrm{ds}\right) \mathrm{dx} ; \mathrm{X}_{0}=0$ and $\mathrm{Y}_{0}=1$;

The absolute error at the final time interval for different sample space numbers, where $\Delta t=\delta t ; R=1$; the step time for discretization of Brownian motion equals to the step time of Euler scheme, are shown in the following (table (A) and Figure (1.1)). As one can see, increasing the number of sample $(\mathrm{N})$ leads to improving the absolute error at the different time steps, where $\Delta t=\delta_{t}$. 
Table (A) : Error generated by the Heun's scheme.

\begin{tabular}{|c|c|c|}
\hline \multirow{2}{*}{$\mathbf{R}$} & $\mathrm{N}$ & Error at final time \\
\hline \multirow{3}{*}{1} & $2^{7}$ & 0.7626 \\
\cline { 2 - 3 } & $2^{8}$ & 0.1032 \\
\cline { 2 - 3 } & $2^{9}$ & 0.3001 \\
\hline \multirow{2}{*}{2} & $2^{7}$ & 0.8550 \\
\cline { 2 - 3 } & $2^{8}$ & 0.2975 \\
\cline { 2 - 3 } & $2^{9}$ & 0.3392 \\
\hline
\end{tabular}

On using $\mathrm{R}=1, \mathrm{~N}=2^{8}$, the following numerical solution is obtained and presented in the following figure (1.1)

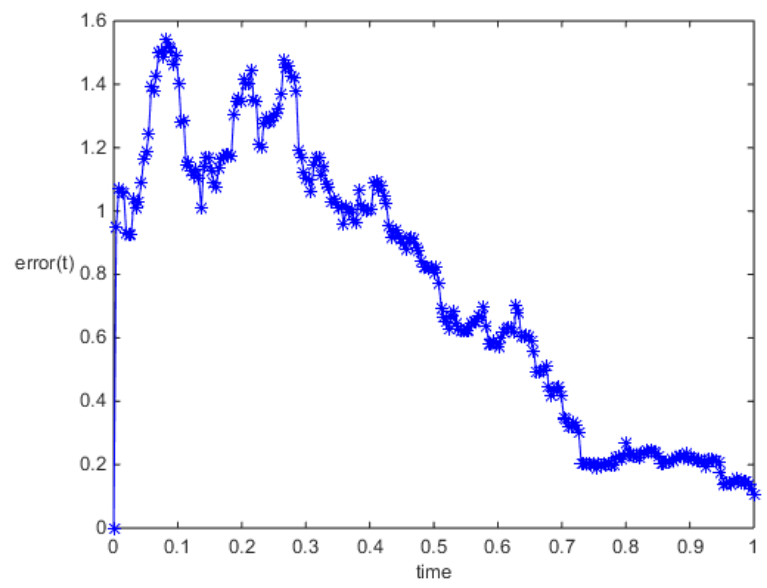

Figure (1.1) : Absolute error between the Heun's scheme and exact

II.Illustration. (With Absolute Error Test) :

Consider the SDE is :

$d X=f d t+g d w$

$X(0)=1$
Where

$f(t)=\int_{0}^{t} \sec \left(\int_{0}^{s} \sin s d s\right) d x ; g(t)$

$=\int_{0}^{\mathrm{t}} \csc \left(\int_{0}^{\mathrm{s}} \cos \mathrm{s} \mathrm{ds}\right) \mathrm{dx} ; \mathrm{X}_{0}=0$ and $\mathrm{Y}_{0}=1$;

As discussed previously in illustration (II), the following table (B) is needed for error analysis and as follows 
Table (B) : Error generated by the Heun's scheme.

\begin{tabular}{|c|c|c|}
\hline \multicolumn{1}{|c|}{$\mathbf{R}$} & $\mathbf{N}$ & Error at final time \\
\hline \multirow{4}{*}{1} & $2^{5}$ & 0.4138 \\
\cline { 2 - 3 } & $2^{6}$ & 1.5409 \\
\cline { 2 - 3 } & $2^{8}$ & 0.2804 \\
\cline { 2 - 3 } & $2^{9}$ & 0.8158 \\
\cline { 2 - 3 } & $2^{10}$ & 0.5493 \\
\cline { 2 - 3 } & $2^{11}$ & 0.3525 \\
\hline
\end{tabular}

On using $\mathrm{R}=1, \mathrm{~N}=2^{8}$, the following numerical solution is obtained and presented in the following figure (1.2)

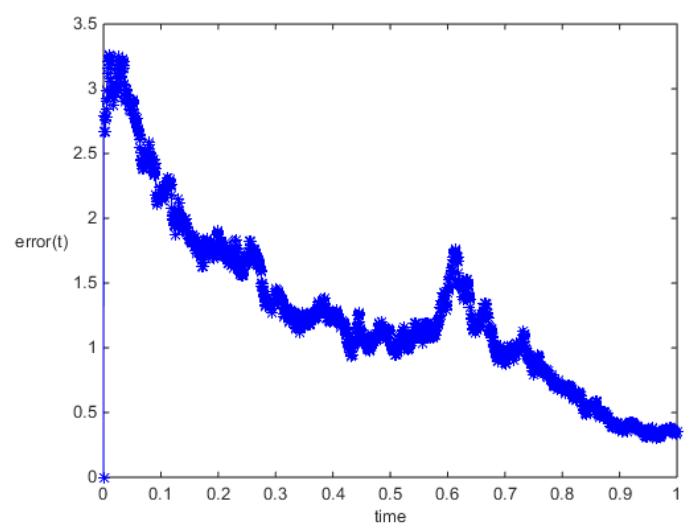

Figure (1.2) : Absolute error between the Heun's scheme and exact

\section{III.Illustration. (With Absolute Error Test) :}

Consider the SDE is :

$d X=f d t+g d W$

$\mathrm{X}(0)=0$
Where $\quad f(t)=\int_{0}^{t} \exp \left(\int_{0}^{s} \sin s d s\right) d x ; g(t)=$ $\int_{0}^{\mathrm{t}} \sin \left(\int_{0}^{\mathrm{s}} \cos \mathrm{s} d \mathrm{~s}\right) \mathrm{dx} ; \mathrm{X}_{0}=0 ; \mathrm{Y}_{0}=1$.

The error at final time interval for $\mathrm{R}=1$ and different number of sample $\mathrm{N}$ is discussed in the following table (C). 
Table (C) : Error generated by the Heun's scheme

\begin{tabular}{|c|c|c|}
\hline $\mathbf{R}$ & $\mathbf{N}$ & Error at final time \\
\hline \multirow{3}{*}{1} & $2^{5}$ & 0.4138 \\
\cline { 2 - 3 } & $2^{8}$ & 0.1032 \\
\cline { 2 - 3 } & $2^{11}$ & 0.1297 \\
\hline
\end{tabular}

One can select $\mathrm{R}=1, \mathrm{~N}=2^{8}$ for accuracy, the following numerical solution is then obtained and presented in the following figure (1.3).

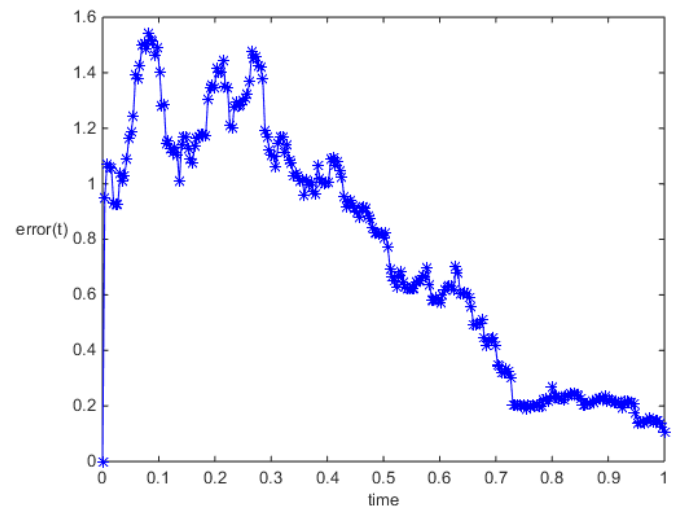

Figure (1.3) : Absolute error between the Heun's scheme and exact

\section{Summary}

Numerical methods for the solution of stochastic differential equations are essential for the analysis of random phenomena. Strong solvers are necessary when exploring characteristics of systems that depend on trajectory-level properties. Several approaches exist for strong solvers, in particular Heun's type methods, although both increase greatly in complication for orders greater than one. In many _ financial applications, major emphasis is placed on the probability distribution of solutions, and in particular mean and variance of the distribution. In such cases, weak solvers may sauce. Independent of the choice of stochastic differential equation solver, methods of variance reduction exist that may increase computational efficiency. The replacement of pseudorandom numbers with quasi random analogues from low-discrepancy sequences is applicable as long as statistical independence along trajectories is maintained. In addition, control variates offer an alternate means of variance reduction and increases inefficiency simulation of stochastic differential equations trajectories.

\section{References}

1.Abdu Khaled M, (2004)., "Mean Square Stability of Second-Order Weak Numerical Methods for Stochastic
Differential Equations", Applied Numerical Mathematics, Vo.48, 127-134.

2. Arnold J. ,(1974), "Stochastic Differential Equations; Theory and Applications", John Wiley and Sons, New York.

3. Bernard P. and Fleury G. ,(2001), "Convergence of Schemes for Stochastic Differential Equations; Monte Carlo Methods", Applied, Vol.7(1), 35-53.

4. Burrage K. and Burrage P. M. ,(1996), "High Strong Order Explicit Runge-Kutta Methods for Stochastic Ordinary Differential Equations", Applied Numerical Mathematics, Vol.22, 81-101.

5.Evans,(2005): Lawrence C. Evance, "An Introduction to Stochastic Differential Equations", Version 1.2, Lecture Notes, Short Course at SIAM Meeting, July, 2005.

6. Fridman,(1975) : AvnerFridman, "Stochastic Differential Equations and Applications", Volume 1, Academic Press, Inc., 1975.

7. Kloeden\& Platen, (1992) : P. E. Kloeden and E. Platen, "Numerical Solution of Stochastic Differential Equations", V.23, Applications of Mathematics, New York, Springer-Verlag, Berlin, 1992.

8. Gard, T. G. Gard, (1988). "Introduction to Stochastic Differential Equations", Marcel Dekker, New York, 
(1988).

9.Glasserman P,Monte Carlo methods in _numerical engineering. Springer, New York(2004).

10. Higham DJ,An algorithmic introduction to numerical simulation of stochastic differential equation,s(2001).

11. Higham DJ, Kloeden P,Numerical methods for nonlinear stochastic differential equations with jumps. Num Math.,(2005).

12. Jentzen A, Kloeden P,Neuenkirch A,Pathwise approximation of stochastic differential equations on domains :

13. higher order convergence rates without global Lipschitz coe_cients. Num Math.,(2008).

14. Kloeden P, Platen E, Schurz H,Numerical solution of SDE through computer experiments. Springer, Berlin,(1994).

15. Lamba H, Mattingly JC, Stuart A,An adaptive EulerMaruyama scheme for SDEs : convergence and stability.(2008).

16. Milstein G.,Numerical integration of stochastic differential equations Kluwer, Dordrecht, (1995). 